\title{
UPAYA MENINGKATKAN LOYALITAS PELANGGAN JASA MARGA TOUR BANDUNG MELALUI SERVICE ENCOUNTER QUALITY
}

\author{
Dina Nur Fathina \\ Elly Malihah \\ HP.Diyah Setyorini \\ Manajemen Pemasaran Pariwisata FPIPS UPI
}

\begin{abstract}
Tourism service business more and more experience progress and certainly influences to increase working field like tour \& travel bureau which offer service to travel arrangement. One company in tour \& travel bureau that develops is Marga Tour Bandung. It focuses to service products into tour package, airlines ticket, and other service. Each service products have the customer. In order to customer loyalty improve continuously, Marga Tour Bandung focuses to how recover employee performance with provide the best service quality when service delivery taking place, on communicating occur between employee and service customer that called service encounter quality. Good service encounter quality will influence customer perception of company service quality, and make the customer continuously to repurchase as the basic to create customer loyalty. Encouraged with premise proposed by Amy Wong (2004:1) that the contact employee in service quality makes an influences customers' behavioral responses in the form of customer loyalty. Sampling in this research is 80 service customer using stratified random sampling technique. While used data analysis technique is simple linear regression analysis technique with SPSS 17.0 for windows program. The study result shows that service encounter quality has significant influence to customer loyalty. Huge of $X$ variable influence to $Y$ variable is $27 \%$. As suggestion for the company is optimize the elements in service encounter quality, recover the system, as well as provide training to employee so that competence in his field and resulting qualified service.
\end{abstract}

Keyword : Service Encounter Quality and Customer Loyalty.

\section{PENDAHULUAN}

\subsection{Latar Belakang Penelitian}

Kondisi pariwisata Indonesia saat ini cukup kondusif dengan berbagai destinasi dan atraksi wisata unik, hingga mampu menyerap wisatawan mancanegara berkunjung. Menurut data yang dikeluarkan BPS, pada tahun 2008 angka tingkat kunjungan wisatawan mancanegara naik secara perlahan hingga tahun 2011. Ini menunjukkan bahwa pemerintah dan stakeholder terkait berhasil membangun industri pariwisata ke arah perkembangan yang positif dan makin menguatkan posisi Indonesia sebagai destinasi wisata yang patut diperhitungkan. Peningkatan pariwisata Indonesia dibuktikan dengan data akhir tahun 2011 yaitu jumlah kedatangan wisatawan mancanegara telah mencapai 7,6 juta melampaui target yang sebelumnya ditetapkan dalam Rencana Strategis (Renstra) yaitu 7,2 juta.

Keberhasilan pariwisata Indonesia tentunya didukung oleh setiap daerah di Indonesia yang memiliki program untuk memajukan pariwisata di daerahnya. Begitu pula dengan pariwisata Kota Bandung yang memiliki ragam wisata yang lengkap dan unik seperti jenis wisata alam, wisata seni \& budaya, wisata heritage, wisata buatan, wisata religi, wisata edukasi, dan juga wisata minat khusus. Agar dapat menanggapi perkembangan pariwisata kota Bandung, maka banyak perusahaan yang bergerak di bidang biro perjalanan wisata yang sangat dibutuhkan oleh wisatawan. Salah satu perusahaan dalam bidang biro perjalanan wisata yang sedang mengembangkan usahanya ialah Marga Tour Bandung.

Produk dan jasa yang ditawarkan Marga Tour ialah tour package (paket wisata 
dan perjalanan wisata), airlines ticketing (tiket pesawat domestik dan internasional), hotel voucher, travel document, transportation (sewa transportasi untuk pariwisata), serta shuttle door to door dari Bandung ke Bandara Soekarno-Hatta. Banyaknya ragam produk yang ditawarkan oleh perusahaan serta ditangani oleh karyawan yang terpercaya menjadikan produk jasa tersebut diminati oleh pasar sasaran.

Kondisi perusahaan mulai stabil ketika tahun 2010 dimana kemajuan perusahaan ditandai dengan banyaknya permintaan dan bertambahnya jumlah pembeli setiap bulan. Oleh karena itu perusahaan menginginkan adanya peningkatan penjualan di tahun 2012 dari setiap lini produk. Tidak sedikit dari pangsa pasar Marga Tour yang telah melakukan pembelian ulang atau pembelian lebih dari satu kali. Kepuasan dan kesan yang baik, dirasakan pembeli saat memenuhi kebutuhan wisatanya. Atas dasar pengalaman itulah pembeli percaya terhadap kualitas jasa Marga Tour dan kembali lagi untuk melakukan pembelian ulang. "Ukuran pertama dari loyalitas mengacu pada perilaku pelanggan yang melakukan pengulangan untuk membeli kembali barang dan jasa yang pernah dinikmati" (Getty dan Thompson dalam jurnal Yohanes, 2007:54). Hal tersebut menunjukkan bahwa Marga Tour berpotensi memiliki pelanggan yang loyal.

Namun pada tahun 2011 tingkat penjualan produk dan jasa mengalami kenaikan sedangkan untuk data pelanggan tahun 2011 mengalami penurunan. Apakah perusahaan kurang memberikan benefit bagi pelanggan sehingga jumlahnya dapat menurun ataukah pelayanan prima yang dijadikan pedoman perusahaan, kurang disampaikan dengan baik terhadap pelanggan. Sementara itu loyalitas dari pelanggan Marga Tour perlu ditingkatkan kembali untuk membantu pencapaian target pada tahun 2012. Sedangkan pelanggan yang loyal merupakan pembeli yang potensial dibandingkan pembeli baru yang belum tentu kembali pada perusahaan untuk melakukan pembelian ulang, sehingga loyalitas pelanggan sangat penting untuk dipertahankan dan ditingkatkan. Fokus utama Marga Tour dalam menjaga loyalitas pelanggan, salah satunya dengan memberikan kualitas terbaik saat pelayanan berlangsung, pada saat terjadi kontak antara karyawan dan pelanggan jasa yang disebut sebagai service encounter. Tingkat kontak dengan pelanggan yang tinggi, membuat kualitas pelayanan saat service encounter (service encounter quality) sangat berpengaruh dalam citra kualitas pelayanan yang diterima pelanggan dan merupakan kesempatan berusaha untuk menjaga kesetiaaan pelanggan.

Kesan terhadap service encounter quality ditentukan oleh proses interaksi dan komunikasi yang berlangsung selama proses penyampaian jasa dan pelanggan pun ikut berperan. Oleh karena itu karyawan harus menguasai empat dimensi dari service encounter quality yaitu profesionalism (profesionalisme), civility (kesopanan), friendliness (keramahan), dan competence (kompetensi) dimana keempat dimensi tersebut merupakan kinerja karyawan. Service encounter quality yang dilaksanakan oleh Marga Tour Bandung bertujuan untuk menciptakan persepsi kualitas jasa yang baik di benak pelanggan. Hal ini menjadikan pelanggan enggan untuk berpindah kepada perusahaan lain, atau yang disebut dengan loyalitas. Berdasarkan latar belakang di atas, maka perlu dilakukan suatu penelitian mengenai "Upaya meningkatkan loyalitas pelanggan jasa Marga Tour Bandung melalui service encounter quality".

\section{KAJIAN PUSTAKA}

\subsection{Kerangka Pemikiran}

Sektor jasa merupakan sektor yang paling besar mengalami perubahan akibat cepatnya perubahan yang dialami faktor lain. Seiring perkembangan jaman, saat ini industri jasa menjadi salah satu sektor penting yang berpengaruh terhadap perekonomian dunia, termasuk di dalamnya adalah sektor jasa pariwisata yang diramaikan oleh persaingan biro perjalanan wisata. Menghadapi persaingan dalam hal 
menciptakan, menyampaikan, dan mengkomunikasikan nilai kepada pasar sasaran, para pengusaha perlu merumuskan strategi pemasaran yang tepat untuk membantu pencapaian target serta tujuan perusahaan.

Para pemasar menggunakan sejumlah alat untuk setiap kegiatan pemasaran jasa yang dilakukan agar dapat membuat tujuan perusahaan dicapai dengan efektif dan efisien. Pemasar menganalisis target pasar yang potensial disesuaikan pula dengan inovasi produk dan jasa yang ditawarkan sehingga banyak konsumen yang mulai tertarik untuk membeli bahkan menjadi pelanggan perusahaan. Dalam mewujudkan hal tersebut, perusahaan jasa terutama industri pariwisata yang tingkat interaksi antara penyedia jasa dan pelanggan cukup tinggi, diperlukan adanya pemahaman mengenai consumer behaviour atau perilaku konsumen. Tujuan utama pemasar adalah melayani dan memenuhi kebutuhan konsumen. Memahami perilaku konsumen dapat menjadikan kinerja dan kualitas jasa perusahaan tersampaikan secara efektif dan tepat sasaran. Konsumen pun akan mendapatkan kepuasan setelah mengkonsumsi jasa tersebut.

Dalam consumer behaviour, terdapat unsur service consumption atau konsumsi jasa di mana unsur tersebut menggambarkan perilaku konsumen dalam mengkonsumsi jasa mulai dari konsumen mencari informasi hingga mengevaluasi jasa yang diterimanya. Saat jasa disampaikan oleh karyawan merupakan hal yang paling kompleks dalam service consumption. Konsumen menginginkan kualitas jasa yang baik dan dapat memenuhi kebutuhannya saat ia menggunakan jasa tersebut. Dengan kata lain pada saat tahap service encounter yaitu terdapat kontak berupa interaksi pribadi antara pelanggan dan karyawan jasa merupakan tahapan paling penting untuk membuktikan kualitas jasa yang diberikan sebuah perusahaan kepada konsumen. Kualitas jasa tersebut tentunya mesti dirasakan konsumen sejak konsumen memulai interaksi dengan karyawan front- line. Selama interaksi dan proses penyampaian jasa berlangsung, sebetulnya konsumen mulai melakukan evaluasi dan menilai kualitas jasa sebuah perusahaan.

Interaksi antara konsumen dengan karyawan sebuah perusahaan jasa memungkinkan timbulnya persepsi konsumen terhadap kualitas jasa perusahaan tersebut. Dengan kata lain, pengertian tersebut mengandung arti bahwa service encounter merupakan titik tolak pelanggan untuk menilai kualitas jasa sebuah perusahaan. Dan bagi perusahaan jasa sendiri, interaksi dengan pelanggan merupakan kesempatan untuk menunjukkan service encounter quality. Dalam hal ini, peran karyawan front-line dinilai sangat penting sebab apa yang disampaikan karyawan front-line dapat mempengaruhi persepsi pelanggan terhadap kepuasan yang ia rasakan. Persepsi pelanggan ini tentunya akan sangat berpengaruh pada perilaku pelanggan untuk kembali melakukan pembelian pada perusahaan jasa yang sama, atau memilih menggunakan jasa dari perusahaan lainnya.

Lebih dalam lagi service encounter dikembangkan menjadi service encounter quality yang mewakili penilaian pelanggan atas seluruh layanan yang ditawarkan oleh perusahaan. Penilaian ini didasarkan pada persepsi yang dirumuskan pelanggan di tahap service encounters. Salah satu faktor penentu suksesnya service encounter quality ialah saat face to face encounter, yakni ketika interaksi bertatap muka antara pelanggan dan penyedia jasa terjadi secara langsung. Setiap pelanggan harus dilayani secara personal sesuai dengan kebutuhan dan preferensinya masing-masing.

Dalam service encounter quality, karyawan memainkan peranan penting untuk meningkatkan persepsi pelanggan terhadap kualitas jasa. Organisasi jasa harus tepat merekrut karyawan yang mempunyai skill, sikap, komitmen, dan kemampuan dalam membina hubungan baik dengan konsumen.

Kualitas jasa saat interaksi berlangsung atau service encounter quality mengenal beberapa dimensi yang masing- 
masing dimensi tersebut menjadi ukuran kualitas pertemuan jasa. Dimensi pada service encounters quality akan membantu perusahaan jasa untuk mengakses tingkat service encounters quality secara akurat, dan kemudian menggunakannya sebagai dasar tinjauan dan pengawasan terhadap upayaupaya perencanaan perusahaan. Diantaranya profesionalisme karyawan, kesopanan karyawan, keramahan karyawan, dan kompetensi karyawan.

Karyawan yang berhubungan langsung dengan pelanggan harus dilatih dan diberikan pengarahan agar memberikan service excellence saat service encounter quality berlangsung. Bagi perusahaan yang bergerak di bidang layanan jasa, service excellence merupakan strategi penting yang harus diberikan kepada pelanggan agar dapat menimbulkan nilai superior, kepuasan pelanggan, keunggulan bersaing, pertumbuhan bisnis, dan profitabilitas yang berdampak pada loyalitas pelanggan.

Loyalitas pelanggan merupakan kesediaan pelanggan untuk senantiasa membeli dan menggunakan produk atau jasa suatu perusahaan dalam jangka waktu yang panjang. Loyalitas pelanggan dinilai sebagai aset perusahaan yang harus dijaga karena menguntungkan perusahaan untuk waktu yang tidak sebentar. Pelanggan yang loyal akan terus melakukan pembelian ulang dan kemungkinan kecil bagi mereka untuk melakukan switching (perpindahan merek). Selain itu, yang tak kalah penting dari keuntungan memiliki pelanggan yang loyal adalah mereka aktif melakukan word of mouth positif kepada orang-orang di sekitarnya.

Kunci utama menumbuhkan loyalitas pelanggan terletak pada keberhasilan interaksi pegawai front line (service encounter) dengan pelanggan (Jill Griffin, 2005:106). Setiap service encounter berkonstribusi pada kepuasan keseluruhan pelanggan dan ketersediannya untuk melakukan bisnis lagi dengan perusahaan yang sama (Fandy Tjiptono, 2006:143). Jayawardhena et al. (2007:575) mengemukakan bahwa "service encounter quality was found to be directly related to customer satisfaction and indirectly to loyalty".

Beberapa pendapat di atas dapat dijadikan acuan bahwa service encounter quality berkaitan dengan upaya menciptakan dan meningkatkan loyalitas pelanggan.

\section{METODE PENELITIAN}

\subsection{Objek Penelitian}

Adapun yang menjadi variabel bebas (independent variable) adalah service encounter quality $(\mathrm{X})$ dan masalah penelitian yang menjadi variabel terikat (dependent variable) yaitu loyalitas pelanggan (Y).

Service encounter quality (independent variable) meliputi empat indikator yaitu professionalism, civility, friendliness, dan competence. Sedangkan loyalitas pelanggan (dependent variable) terdiri dari empat indikator yaitu melakukan pembelian berulang, membeli antarlini produk dan jasa, mereferensikan kepada orang lain, dan menunjukkan kekebalan terhadap tarikan pesaing. Pada penelitian ini, objek yang dijadikan responden adalah pelanggan jasa Marga Tour Bandung.

\subsection{Jenis Penelitian \& Metode Penelitian yang Digunakan}

Berdasarkan variabel-variabel yang diteliti maka jenis penelitian ini adalah penelitian deskriptif dan verifikatif. Penelitian deskriptif dalam penelitian ini bertujuan untuk memperoleh gambaran mengenai service encounter quality dan gambaran mengenai loyalitas pelanggan. Sedangkan penelitian verifikatif bertujuan untuk menguji kebenaran hipotesis yang dilakukan melalui pengumpulan data di lapangan. Dalam hal ini penelitian verifikatif bertujuan untuk mengetahui pengaruh service encounter quality terhadap loyalitas pelanggan.

Berdasarkan jenis penelitian, maka metode yang digunakan adalah explanatory survey, dimana informasi dari populasi mengenai service encounter quality yang telah dijalankan oleh Marga Tour Bandung dan gambaran loyalitas pelanggan yang dikumpulkan langsung dari tempat kejadian 
secara empirik dengan tujuan untuk mengetahui pendapat dari sebagian populasi atau sejumlah sampel yang telah ditentukan.

\subsection{Populasi}

Populasi pada penelitian ini adalah 282 pelanggan jasa Marga Tour Bandung tahun 2010-2011 yang telah melakukan pembelian ulang pada produk jasa tour, tiket pesawat, ataupun jasa lain (voucher hotel, sewa transportasi, dokumen perjalanan, dan shuttle bandara). Dimana pelanggan yang melakukan pembelian ulang merupakan dasar dari loyalitas pelanggan.

\subsection{Sampel}

Dalam menghitung ukuran sampel (n) dari populasi $(\mathrm{N})$ yang telah ditetapkan, maka dapat menggunakan rumus teknik Slovin (Husein Umar, 2009:78), dengan hasil perhitungan yaitu 74 responden. Jadi untuk mengantisipasi kesalahan dalam penelitian ini, maka ukuran sampel ditambah sebanyak 6 sampel sehingga ukuran minimal sampelnya menjadi 80 responden.

\subsection{Teknik Sampel}

Demi mendapatkan sampel representatif maka dalam penelitian ini digunakan teknik stratified random sampling yang termasuk ke dalam kategori probability sampling, teknik ini digunakan bila populasi mempunyai unsur yang tidak homogen dan berstrata secara proporsional (Sugiyono, 2010:118)

\subsection{Rancangan Analisis Data}

$\begin{array}{ll}\begin{array}{l}\text { 3.6.1 Rancangan Analisis Data } \\ \text { Deskriptif }\end{array} & \\ \text { Penelitian ini menggunakan } \\ \text { analisis deskriptif }\end{array}$
mendeskripsikan variabel-variabel penelitian, antara lain :

1. Analisis deskriptif tentang service encounter quality di Marga Tour Bandung.

2. Analisis deskriptif tentang loyalitas pelanggan di Marga Tour Bandung.

Analisis deskriptif yaitu menganalisis data dengan cara mendeskripsikan atau menggambarkan data yang telah terkumpul yang berasal dari jawaban responden atas item-item dalam kuesioner.

Skala pengukuran yang digunakan dalam penelitian ini adalah skala likert. Menurut Sugiyono (2010:132) "Skala likert digunakan untuk mengukur sikap, pendapat, dan persepsi seseorang atau sekelompok orang tentang fenomena sosial". Dengan skala likert, variabel yang akan diukur dijabarkan menjadi indikator. Kemudian indikator tersebut dijadikan titik tolak untuk menyusun item-item instrumen yang berupa pertanyaan. Pengukuran skala likert dimulai dari nilai 1 (sangat tidak baik) hingga nilai 5 (sangat baik).

\subsubsection{Rancangan Analisis Data Verifikatif}

Teknik analisis data yang digunakan dalam penelitian ini adalah análisis regresi linear sederhana yaitu didasarkan pada hubungan fungsional ataupun kausal satu variabel independen dengan satu variabel dependen (Sugiyono, 2010:270). Dalam penelitian ini análisis regresi linear sederhana digunakan untuk mengetahui pengaruh antara variabel independen (X) yaitu service encounter quality terhadap variabel dependen (Y) yaitu loyalitas pelanggan jasa Marga Tour Bandung.

Teknik analisis regresi linear sederhana dilakukan dengan prosedur kerja sebagai berikut:

1. Uji Asumsi Regresi : penggunaan metode analisis regresi linear sederhana memerlukan asumsi klasik yang secara statistik harus dipenuhi.

2. Mengetahui kuat rendahnya hubungan pengaruh

3. Koefisien Determinasi, digunakan untuk mengetahui persentase pengaruh yang terjadi dari variabel bebas terhadap variabel terikat.

\subsection{Pengujian Hipotesis}

Berdasarkan hipotesis konseptual yang diajukan yaitu terdapat pengaruh yang signifikan antara service encounter quality (X) terhadap loyalitas pelanggan (Y), maka terlebih dahulu hipotesis konseptual tersebut digambarkan dalam sebuah paradigma seperti pada Gambar 3.1 berikut: 


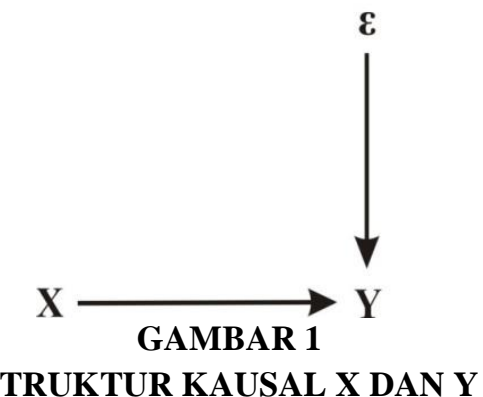

Keterangan:

$$
\begin{array}{cc}
\mathrm{X} & \text { : variabel Service Encounter Quality } \\
\mathrm{Y} & \text { : variabel Loyalitas Pelanggan } \\
\varepsilon & \text { : residu (variabel lain diluar variabel X } \\
& \text { yang berpengaruh) }
\end{array}
$$

Hipotesis yang akan diuji yaitu loyalitas pelanggan jasa Marga Tour Bandung (Y) melalui service encounter quality (X) dalam rangka pengambilan keputusan penerimaan atau penolakan, hipotesis dapat di tulis sebagai berikut:

$\mathrm{H}_{0}=0$, Tidak terdapat pengaruh yang signifikan antara service encounter quality terhadap loyalitas pelanggan jasa Marga Tour Bandung.

$\mathrm{H}_{\mathrm{a}} \neq 0$, Terdapat pengaruh yang signifikan antara service encounter quality terhadap loyalitas pelanggan jasa Marga Tour Bandung.

\section{HASIL PENELITIAN DAN PEMBAHASAN \\ 4.1 Tanggapan Pelanggan Jasa Terhadap Service Encounter Quality di Marga Tour Bandung \\ Berdasarkan hasil rekapitulasi tanggapan pelanggan jasa Marga Tour Bandung terhadap service encounter quality di atas dapat dilihat bahwa skor total untuk service encounter quality adalah 5.199. Jumlah skor tersebut digambarkan ke dalam garis kontinum yaitu sebagai berikut:}

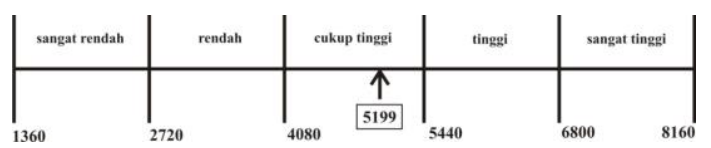

Sumber : Hasil Pengolahan Data 2012

GAMBAR 4.1

GARIS KONTINUM SERVICE ENCOUNTER QUALITY
DI MARGA TOUR BANDUNG

\subsection{Tanggapan Pelanggan Jasa Terhadap Loyalitas Pelanggan di Marga Tour Bandung}

Berdasarkan hasil rekapitulasi yang telah dijelaskan di atas, dapat dilihat bahwa skor total untuk loyalitas pelanggan adalah 1642. Jumlah skor tersebut digambarkan ke dalam garis kontinum yaitu sebagai berikut:

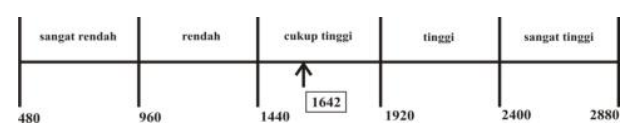

Sumber : Hasil Pengolahan Data 2012

GAMBAR 4.2

\section{GARIS KONTINUM LOYALITAS PELANGGAN \\ DI MARGA TOUR BANDUNG}

\subsection{Pengaruh Service Encounter Quality Terhadap Loyalitas Pelanggan Jasa Marga Tour Bandung}

\begin{abstract}
Berdasarkan hipotesis yang diajukan dan jenis data yang dikumpulkan, maka teknik analisis data yang digunakan dalam penelitian ini adalah analisis regresi linear sederhana untuk mengetahui besarnya pengaruh service encounter quality (X) terhadap loyalitas pelanggan $(\mathrm{Y})$.
\end{abstract}

\subsubsection{Pengujian Koefisien Korelasi dan Koefisien Determinasi}

Koefisien korelasi digunakan untuk mengetahui seberapa besar hubungan antara variabel $\mathrm{X}$ terhadap variabel $\mathrm{Y}$.

Hasil analisis Tabel 4.3 menunjukkan bahwa nilai koefisien korelasi adalah sebesar 0,519. Hal tersebut menunjukan bahwa terdapat hubungan antara service encounter quality $(\mathrm{X})$ dengan loyalitas pelanggan $(\mathrm{Y})$ yaitu sebesar 0,519. Jika mengacu pada Sugiyono (2010:250), maka korelasi antara X dan Y pada penelitian ini berada dalam kategori hubungan sedang $(0,400-0,599)$.

Koefisien Determinasi 
Untuk mengetahui besarnya pengaruh variabel $\mathrm{X}$ terhadap $\mathrm{Y}$, maka dapat dilihat dari kolom R Square pada Tabel 4.3, nilai koefisien determinasi adalah 0,27 dikalikan $100 \%$ ialah sebesar $27 \%$. Hal ini menunjukkan bahwa prosentase sumbangan pengaruh variabel $\mathrm{X}$ yaitu service encounter quality terhadap variabel $\mathrm{Y}$ loyalitas pelanggan sebesar $27 \%$.

\subsubsection{Analisis Regresi Linear Sederhana}

Pengujian ini bertujuan untuk melihat pengaruh variabel bebas yaitu service encounter quality terhadap variabel terikat yaitu loyalitas pelanggan. Berikut ini adalah hasil perhitungan uji $t$ hitung dan taraf signifikansinya pada penelitian ini:

TABEL 4.4

OUTPUT KOEFISIEN REGRESI

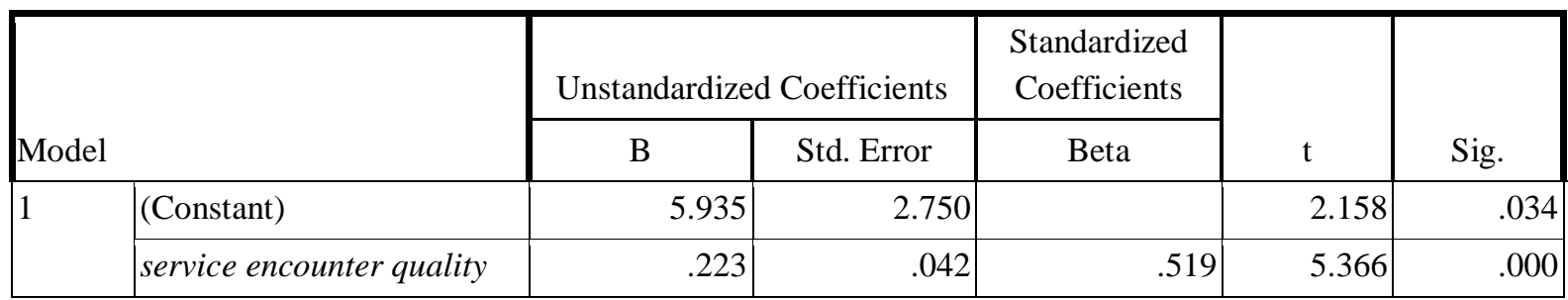

a. Dependent Variable: loyalitas pelanggan

Sumber : Hasil Pengolahan Data 2012

Tabel tersebut menunjukkan terdapat pengaruh yang signifikan antara variabel service encounter quality terhadap loyalitas pelanggan $\left(t_{\text {hitung }}=5,366>1,991=t_{\text {tabel }}\right)$, demikian juga nilai $\operatorname{sig}=0,000<0,05$. Sehingga dapat disimpulkan bahwa nilai $t_{\text {hitung }}>$ $\mathrm{t}_{\text {tabel }}$ maka $\mathrm{H}_{0}$ ditolak dan $\mathrm{H}_{\mathrm{a}}$ diterima, artinya service encounter quality berpengaruh signifikan terhadap loyalitas pelanggan.

\section{KESIMPULAN}

\subsection{Kesimpulan}

1. Secara umum gambaran service encounter quality di Marga Tour Bandung yang terdiri dari indikator professionalism, civility, friendliness, dan competence telah dilaksanakan cukup baik.

2. Secara umum gambaran loyalitas pelanggan jasa di Marga Tour Bandung cukup tinggi.

3. Berdasarkan pengujian hipotesis dengan teknik analisis regresi sederhana menunjukkan terdapat pengaruh yang signifikan antara service encounter quality terhadap loyalitas pelanggan. Besarnya koefesien determinasi sumbangan pengaruh variabel $\mathrm{X}$ yaitu service encounter quality terhadap variabel $\mathrm{Y}$ loyalitas pelanggan sebesar $27 \%$.
Pengaruh tersebut memang tergolong kecil, dan pengaruh lainnya kemungkinan besar ada pada faktorfaktor lain seperti lokasi, harga, dan produk yang tidak diteliti oleh penulis.

\section{DAFTAR PUSTAKA}

Ari Wijayanti. (2007). Strategi Meningkatkan Loyalitas Melalui Kepuasan Pelanggan. Program Studi Magister Manajemen Universitas Dipenogoro.

Balaji.B., (2002). Service Marketing and Management. New Delhi: S.Chand \& Company

Bitner,Mary Jo.,(1990). Evaluating Service Encounters: The Effects of Physical Surrounding and Employee Respones. Journal of Marketing : Vol.54

Coltman,Tim R., (2010). Realigning Service Operation Strategy at DHL express. Australia: University of Wollongong

Dwi Priyatno. (2011). Buku Saku SPSS Analisis Statistik Data Lebih Cepat, Efisien, dan Akurat. Jakarta: MediaKom 
Farida Jasfar. (2009). Manajemen Jasa Pendekatan Terpadu. Ciawi Bogor: Ghalia Indonesia.

Fandy Tjiptono. (2007). Pemasaran Jasa. Malang: Bayumedia Publishing.

Fandy Tjiptono dan Gregorius Chandra. (2007). Service Quality \& Satisfaction. Yogyakarta: ANDI

Franky Slamet.(2008). Kepuasan dan Loyalitas Pelanggan. Jurnal Manajemen No.02

Gamal Suwantoro. (2004). Dasar-Dasar Pariwisata. Yogyakarta: ANDI

Griffin, Jill. (2005). Customer Loyalty. Jakarta: Erlangga

Husein Umar. (2009). Metode Penelitian Untuk Skripsi dan Tesis Bisnis Edisi Kedua. Jakarta: Rajawali Pers.

Jayawardhena,Chanaka., et al., (2007). Outcomes of Service Encounter Quality in a Business to Business Context. Journal of Industrial Marketing Management: Vol 36

Kotler, Philip dan Gary Amstrong. (2012). Prnciples of Marketing ; $14^{\text {th }}$ edition. New Jersey: Prentice Hall.

Kotler, Philip dan Kevin Lane Keller. (2009). Manajemen Pemasaran ; $13^{\text {th }}$ edition. New Jersey: Prentice Hall.

Liang Kheng,Lo., et al., (2010). The Impact of Service Quality on Customer Loyalty. International Journal of Marketing Studies : Vol.2

Lovelock Christopher dan Lauren Wirtz. (2011). Service Marketing $7^{\text {th }} e d$. New Jersey: Pearson Hall

M Adil, Haq. (2010). Jurnal Biro Perjalanan Wisata.

Muljadi,AJ. (2009). Kepariwisataan dan Perjalanan. Jakarta : Rajagrafindo Persada

Nasution. (2003). Metode Research. Jakarta : Bumi Aksara

Oka A.Yoeti. (2001). Tours and Travel Management. Jakarta : Penebar Swadaya

Raajpot,Nusser, (2004). Reconceptualizing Service Encounter Quality in a Non-
Western Context. Journal of Service Research: vol 7 no.2

Ratih Hurriyati.(2008). Bauran Pemasaran dan Loyalitas Konsumen. Bandung : Alfabeta

Riduwan.(2009). Pengantar Statistika Sosial. Bandung : Alfabeta

Smith, Amy K., et al., (1999). A Model of Customer Satisfaction with Service Encounters Involving Failure and Recovery. American Marketing Association : Journal of Marketing Research

Sri Raharso. (2008). Service Encounter Meningkatkan Persepsi Kualitas Jasa Melalui Perilaku Karyawan. Jurusan Administrasi Niaga Politeknik Negeri Bandung

Sudjana (2003). Teknik Analisis Regresi dan Korelasi bagi Para Peneliti. Bandung: Tarsito

Sugiyono. (2010). Metode Penelitian Bisnis. Bandung: Alfabeta

Suharsimi Arikunto (2010). Prosedur Penelitian: Suatu Pendekatan Praktik (edisi revisi 2010). Jakarta: PT. Rineka Cipta

Surprenant,Carol F dan Michael R.Solomon., (1987). Predictability and Personalization in the Service Encounter. Journal of Marketing vol.51

Theresia Tanihaha. (2009). The Role of Emotional Satisfaction in Service Encounter for Department Stores in Jakarta. Jakarta: Journal of Business Strategy and Execution.

Wong,Amy., (2004). The Role of Emotional Satisfaction in Service Encounters. Journal Managing Service Quality Vol 14. Emerald Group Publishing.

Yohanes Sugiharto. (2007). Pengaruh Kepuasan terhadap Loyalitas Pelanggan. Semarang: VISI edisi XVIII/2007.

Zeithaml, V.A., M.J. Bitner (2009). Service Marketing: Intergrating Customer Focus Across the Firm, $5^{\text {th }} e d$., McGraw-Hill. Boston 